\title{
Influence of heart failure on the prognosis of patients with acute myocardial infarction in southwestern China
}

\author{
FUXUE DENG $^{1}$, YONG XIA ${ }^{2}$, MICHAEL FU $^{3}$, YUNFENG HU ${ }^{1}$, FANG JIA ${ }^{4}$, \\ YEFFRY RAHARDJO $^{1}$, YINGYI DUAN ${ }^{1}$, LINJING HE ${ }^{1}$ and JING CHANG ${ }^{1}$ \\ ${ }^{1}$ Department of Cardiology, The First Affiliated Hospital of Chongqing Medical University, Chongqing 404100, P.R. China; \\ ${ }^{2}$ Heart \& Lung Research Institute, The Ohio State University College of Medicine, Columbus, OH 43210, USA; \\ ${ }^{3}$ Section of Cardiology, Sahlgrenska University Hospital/Östra Hospital, Gothenburg 40530, Sweden; \\ ${ }^{4}$ Department of Internal Medicine, The Second Affiliated Hospital of Chongqing Medical University, \\ Chongqing 404100, P.R. China
}

Received August 30, 2015; Accepted December 21, 2015

DOI: $10.3892 /$ etm.2016.3211

\begin{abstract}
The impact of heart failure (HF) on acute myocardial infarction (AMI) in patients from southwestern China remains unclear. The present study aimed to compare in-hospital cardiovascular events, mortality and clinical therapies in AMI patients with or without HF in southwestern China. In total, 591 patients with AMI hospitalized between February 2009 and December 2012 were examined; those with a history of HF were excluded. The patients were divided into four groups according to AMI type (ST-elevated or non-ST-elevated AMI) and the presence of HF during hospitalization. Clinical characteristics, in-hospital cardiovascular events, mortality, coronary angiography and treatment were compared. Clinical therapies, specifically evidence-based drug use were analyzed in patients with HF during hospitalization, including angiotensin converting enzyme inhibitors (ACEIs) and $\beta$-blockers (BBs). AMI patients with HF had a higher frequency of co-morbidities, lower left ventricular ejection fraction, longer length of hospital stay and a greater risk of in-hospital mortality compared with AMI patients without HF. AMI patients with HF were less likely to be examined by cardiac angiography or treated with reperfusion therapy or recommended medications. AMI patients with HF co-treated with ACEIs and BBs had a significantly higher survival rate (94.4 vs. 67.5\%; $\mathrm{P}<0.001$ ) compared with untreated patients or patients treated with either ACEIs or BBs alone. Logistic regression analysis revealed that $\mathrm{HF}$ and cardiogenic shock in patients with AMI were the strongest predictors of in-hospital mortality. AMI patients with HF were at a higher risk of
\end{abstract}

Correspondence to: Professor Jing Chang, Department of Cardiology, The First Affiliated Hospital of Chongqing Medical University, 1 Friendship Road, Chongqing 404100, P.R. China E-mail: cnJingChang@126.com

Key words: acute myocardial infarction, heart failure, in-hospital mortality, in-hospital cardiovascular events adverse outcomes. Cardiac angiography and timely standard recommended medications were associated with improved clinical outcomes.

\section{Introduction}

Coronary artery disease (CAD) is the single most frequent cause of death worldwide; nearly 7.4 million individuals succumb to CAD every year, accounting for $13.1 \%$ of all deaths (1). Furthermore, in patients with CAD, acute myocardial infarction (AMI) is the twelfth leading cause of cardiac death (2). Each year, $>3$ and 4 million individuals suffer from ST-elevated myocardial infarction (STEMI) and non-ST-elevated myocardial infarction (NSTEMI), respectively (3). China is the largest of the 16 developing countries, with a rapidly developing economy; in China, $\geq 500,000$ individuals have AMI out of a total of 2 million cardiovascular disease cases annually (4). According to research conducted by Hopkin University, 45\% of the adult population has $\geq 1$ chronic disease; this proportion increases to $90 \%$ in individuals $>65$ years of age, who represent more than half of patients with myocardial infarction $(5,6)$. Unfortunately, following AMI, neurohormonal systems that promote pathological ventricular remodeling and progressive myocardial damage are activated (7); patients consequently develop HF due to an impairment of left ventricular myocardial function (8), which is associated with high morbidity and mortality. The appropriate management of AMI, including pharmacology, thrombolysis and invasive therapy, may marginally decrease vascular complications, composite bleeding complications and mortality (9). However, treatment strategy varies with age, gender, ethnicity, clinical circumstance and socioeconomic status. In addition, ethnic differences in etiology, outcome and response to therapy in patients with $\mathrm{HF}$ and discrepancies in clinical practice require validation $(10,11)$. Numerous studies have been conducted on $\mathrm{HF}$ rates and the beneficial clinical effects of evidence-based drug therapy have been demonstrated in western countries $(12,13)$. Chongqing is the biggest industrial and commercial center in southwest China and is diverse in ethnicity, living standards and population (14). However, little is known with regards to 
the characteristics, prognosis of HF following AMI and HF medications in patients from China and other Asian countries in clinical practice. The present study aimed to compare the baseline clinical profile, clinical treatment in clinical practice, cardiovascular events and in-hospital mortality rates of AMI patients with and without HF in southwestern China.

\section{Materials and methods}

Ethics statement. The present investigation was approved by the ethics committee of the First Affiliated Hospital of Chongqing Medical University (Chongqing, China). Informed consent was not obtained since this was a retrospective study and the study protocol conformed to the ethical guidelines of the Declaration of Helsinki. The patients' information was anonymized and de-identified when the data were collected and analyzed.

Study design and population. Patients who were hospitalized in the First Affiliated Hospital of Chongqing Medical University due to AMI (including STEMI and NSTEMI) between February 2009 and December 2012 were recruited. Patients $<18$ years old, those who suffered from stable or unstable angina instead of myocardial infarction and those with a history of HF, congenital heart diseases, valvular heart diseases, cardiomyopathy, viral myocarditis, sarcoidosis, or severe arrhythmias were excluded from the study. A total of 591 patients were included in the investigation and identified according to the HF status and the type of AMI.

Data were collected retrospectively from hospital records, including clinical characteristics, initial evaluations, therapeutic management, major cardiovascular events (MACEs) and in-hospital mortality and were compared between the two groups of AMI patients. The use of the evidence-based drugs, including angiotensin converting enzyme inhibitors (ACEIs) and $\beta$-blockers (BBs), in AMI patients with HF in clinical practice during hospitalization was further analyzed. Accordingly, patients were divided into two groups: Patients receiving co-treatment with $\mathrm{BBs}$ and ACEIs and patients either receiving no treatment or treated with BBs or ACEIs alone.

Diagnostic criteria. All 591 patients suffered from AMI on at least one occasion. AMI patients with HF during hospitalization was defined as: i) Simultaneous presentation of AMI and HF; or ii) development of HF during hospitalization for AMI in a patient with no previous history of HF due to other diseases.

According to the European Society of Cardiology, the American College of Cardiology Foundation, the American Heart Association and the World Heart Federation universal definition of AMI (2012) (15) and a previous study (16), the diagnosis of STEMI was defined by the following criteria: i) Chest pain lasting for $\geq 30$ min that could not be completely relieved by nitrates; ii) new ST segment elevation present at the $\mathrm{J}$ point in two or more contiguous leads; iii) increase in serum levels of creatine kinase, creatine kinase MB (CKMB) fraction, or troponins to more than twice the upper limit of normal levels; and/or iv) evidence of diseased vessels as determined by cardiac angiography. A diagnosis of NSTEMI was accepted in the absence of ST-segment elevation, the presence of ischemic
ST-segment or T-wave changes for $\geq 24 \mathrm{~h}$ with positive cardiac enzymes and/or a typical clinical presentation. Chronic obstructive pulmonary disease (COPD) was diagnosed by physicians according to patient clinical respiratory symptoms (dyspnea, cough and/or sputum production), laboratory test results (including blood gas analysis and oxygen saturation) and case histories.

The diagnosis of HF in the present study was based on the following conditions, which were predominantly established from the European Society of Cardiology guideline for AMI-associated HF (17): i) Onset of cardinal manifestations of HF (such as dyspnea and fatigue); ii) rales in more than one-third of the lung field (Killip class II or higher); iii) pulmonary edema or congestion on chest radiography, with no indication of a non-cardiac cause; and/or iv) varying degrees of abnormal brain natriuretic peptide or $\mathrm{N}$-terminal pro $\beta$-type natriuretic peptide levels. MACEs included atrial fibrillation, ventricular arrhythmia, major bleeding, cardiogenic shock, recurrent ischemia and recurrent myocardial infarction.

Cardiogenic shock was defined as systolic blood pressure $<80 \mathrm{mmHg}$ in the absence of hypovolemia and associated with cyanosis, cold extremities, changes in mental status and persistent oliguria (18). Bleeding complications were assessed by the Thrombolysis In Myocardial Infarction criteria and were classified as major bleeding (intracranial, overt bleeding with a $>50 \mathrm{~g} / 1$ reduction in hemoglobin levels, or hematocrit $>15 \%$ ) or minor bleeding (spontaneous gross hematuria or hematemesis with a $>30 \mathrm{~g} / \mathrm{l}$ reduction in hemoglobin levels and $\mathrm{a}<15 \%$ reduction in hematocrit) (19).

Statistical analyses. Clinical characteristic data were analyzed using $\chi^{2}$ tests for discrete variables and two-tailed Student's t-tests for continuous variables and were presented as the number (frequency) and mean \pm standard deviation, respectively. Non-normal continuous variables were analyzed using a Mann-Whitney U-test and were presented as the median and range. In addition, logistic regression analysis was performed using a backward selection model in the following order: i) Presence of post-AMI HF; ii) risk factors such as age, gender, heart rate, smoking, drinking, diabetes, hypertension, COPD, history of angina, prior stroke, chronic renal failure, hyperlipidemia, family history of coronary artery disease, history of myocardial infarction, STEMI/NSTEMI myocardial infarction type at presentation, hospitalization, left ventricular ejection fraction (LVEF), CKMB and length of hospital stay; iii) in-hospital events, including atrial fibrillation and ventricular arrhythmia, re-ischemia, major bleeding, re-infarction and cardiogenic shock; iv) medications during hospitalization, including antiarrhythmic, oral BBs, calcium-channel blockers, ACEIs or angiotensin receptor blockers, aspirin and heparin; and v) cardiac angiography and primary reperfusion strategies, including thrombolysis and percutaneous coronary intervention (PCI). As numerous variables were entered into the logistic regression model, tests for multicollinearity between variables were performed. A covariance matrix did not demonstrate significant multicollinearity and tolerance values of all variables in a linear regression model were high, indicating low multicollinearity. 


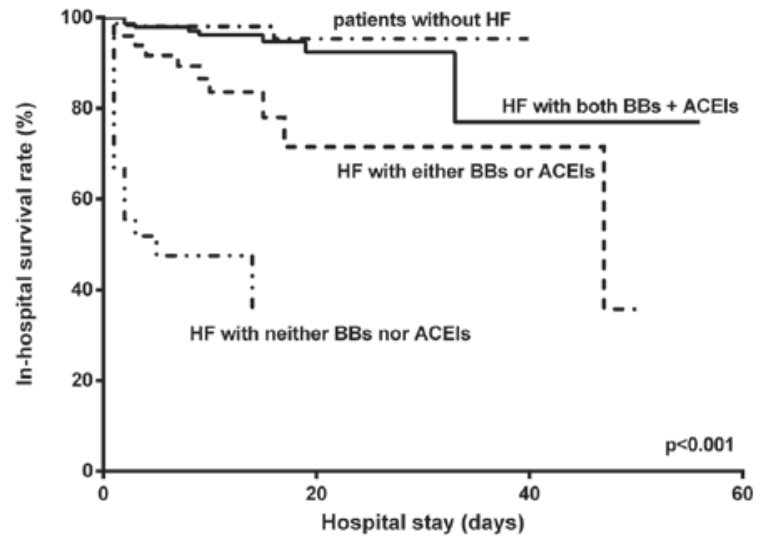

Figure 1. Comparison of unadjusted in-hospital survival rates among the study groups. Unadjusted in-hospital survival rates among patients without HF $(n=369)$, patients with HF treated with both BBs and ACEIs $(n=142)$, patients with $\mathrm{HF}$ treated with either drug class $(\mathrm{n}=50)$, and patients with HF receiving no treatment $(\mathrm{n}=30)$ during their hospital stay. $\mathrm{HF}$, heart failure; BBs, $\beta$-blockers; ACEIs, angiotensin-converting enzyme inhibitors.

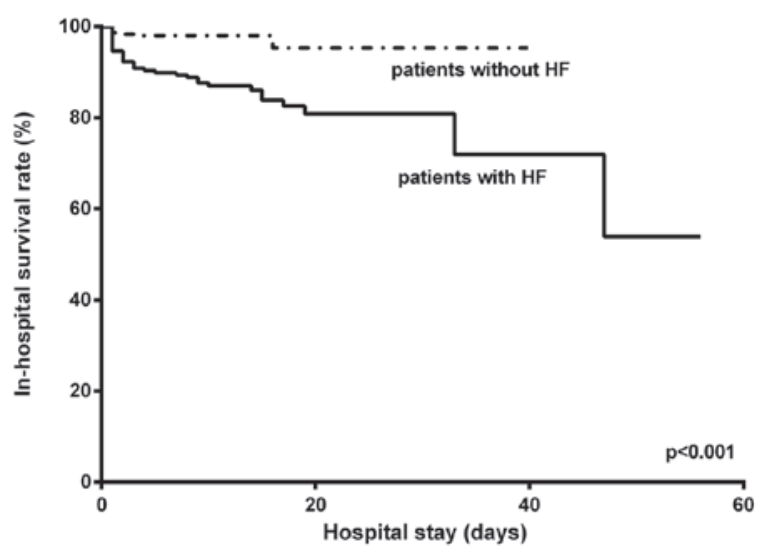

Figure 2. In-hospital survival rates of patients with or without HF during their hospital stay $(\mathrm{P}<0.001)$. Patients with heart failure, 222 individuals; patients without heart failure, 369 individuals. HF, heart failure.

Due to the limited follow-up period in this study, the entire length of hospital stay tended to correlate with several risk factors and in-hospital mortality. The in-hospital survival curve was calculated using the Kaplan-Meier method and a log-rank test (Figs. 1-3) and $\chi^{2}$ test (Fig. 4) were used to compare groups. Statistical analyses were performed using SPSS software version 18.0 (SPSS, Inc., Chicago, IL, USA). $\mathrm{P}<0.05$ was considered to indicate a statistically significant result for all tests.

\section{Results}

Baseline characteristics. The overall demographic and baseline characteristics of patients with or without first and new-onset HF following STEMI or NSTEMI are shown in Table I. Among the 412 STEMI and 179 NSTEMI patients, 162 (38.3\%) and $60(33.5 \%)$, respectively, developed first and new-onset HF during hospitalization. Patients with both STEMI and NSTEMI who developed in-hospital HF were significantly older and had a higher rate of renal failure $(\mathrm{P}<0.05)$. In addition, these patients had a higher heart rate, lower LVEF and a higher rate

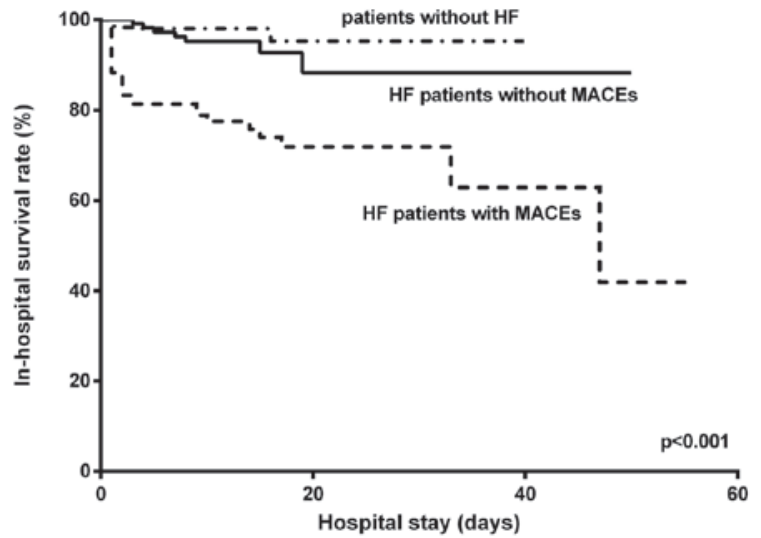

Figure 3. In-hospital survival rates of non-HF patients, HF patients with MACEs, and those without MACEs $(\mathrm{P}<0.001)$. Patients without HF, 369 individuals; HF patients with MACEs, 103 individuals; HF patients without MACEs, 119 individuals. MACEs included atrial fibrillation, ventricular arrhythmia, major bleeding, cardiogenic shock, recurrent ischemia, and recurrent myocardial infarction. HF, heart failure; MACEs, major cardiovascular events.

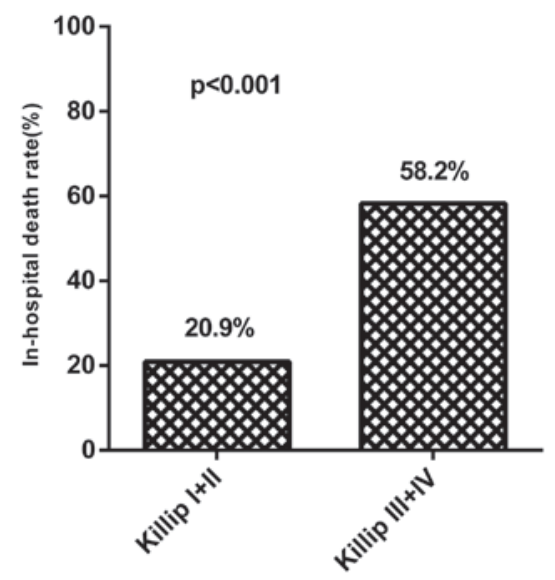

Figure 4. In-hospital mortality rates among HF patients with various Killip classes $(\mathrm{P}<0.001)$. Killip class I-IV, patients with post-acute myocardial infarction HF. HF, heart failure.

of arrhythmia on admission $(\mathrm{P}<0.05)$, and the rate of atrial fibrillation on admission was significantly higher in NSTEMI patients with HF $(\mathrm{P}<0.001)$. The rate of ventricular arrhythmia did not differ significantly in either STEMI and NSTEMI patients according to HF. A preserved LVEF $(\geq 51 \%)$ was noted in $63.6 \%$ of STEMI patients and in $63.3 \%$ of NSTEMI patients who developed HF following hospitalization. However, STEMI patients with $\mathrm{HF}$ were more likely to have a history of COPD and a longer delay prior to hospital presentation $(\mathrm{P}<0.05)$. Accordingly, the peak CKMB value for STEMI patients with in-hospital HF was significantly higher compared with that for STEMI patients without HF and the peak serum creatinine and urea nitrogen values were also higher in HF patients with both AMI types. A further analysis of post-AMI HF in patients with STEMI showed that $57.4 \%$ of patients had Killip class II AMI, $17.9 \%$ had Killip class III AMI and $21.6 \%$ had Killip class IV AMI. Among the patients with NSTEMI, 70\% had Killip class II AMI, $16.7 \%$ had Killip class III AMI and $13.3 \%$ had Killip class IV AMI. 


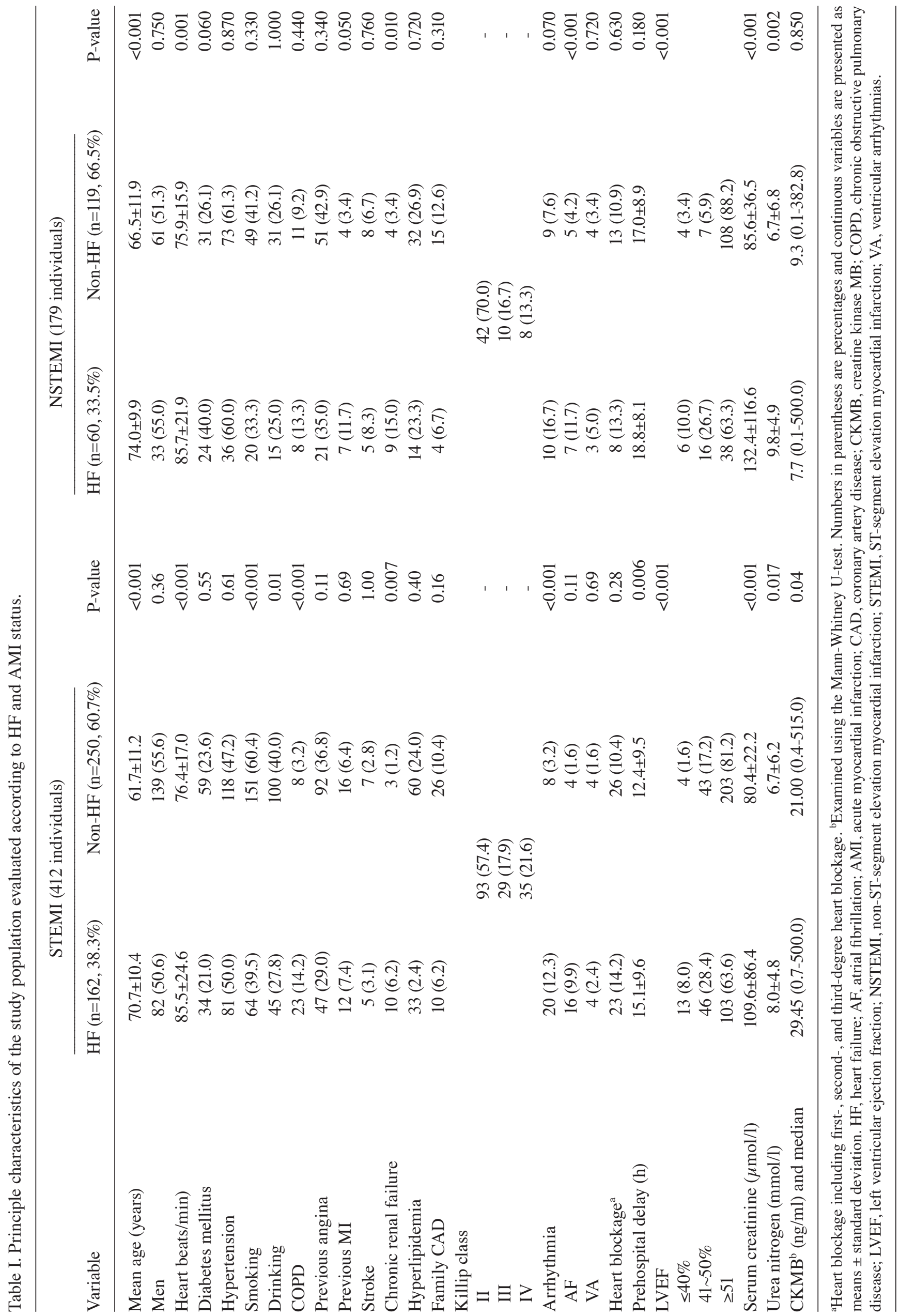


Table II. Medical treatment during hospitalization $(\mathrm{n}=591)$.

\begin{tabular}{|c|c|c|c|c|c|c|}
\hline \multirow[b]{2}{*}{ Variable } & \multicolumn{2}{|c|}{ STEMI } & \multirow[b]{2}{*}{ P-value } & \multicolumn{2}{|c|}{ NSTEMI } & \multirow[b]{2}{*}{ P-value } \\
\hline & $\begin{array}{c}\mathrm{HF} \\
(n=162)\end{array}$ & $\begin{array}{l}\text { Non-HF } \\
(n=250)\end{array}$ & & $\begin{array}{c}\text { HF } \\
(n=60)\end{array}$ & $\begin{array}{l}\text { Non-HF } \\
(n=119)\end{array}$ & \\
\hline \multicolumn{7}{|l|}{ Treatment } \\
\hline Antiarrhythmic agents & $28(17.3)$ & $23(9.2)$ & 0.020 & $13(21.7)$ & $3(2.5)$ & $<0.001$ \\
\hline$\beta$-blockers & $121(74.7)$ & $204(81.6)$ & 0.110 & $54(90.0)$ & $101(84.9)$ & 0.490 \\
\hline $\mathrm{CCB}$ & $38(23.5)$ & $53(21.2)$ & 0.630 & $19(31.7)$ & $38(31.9)$ & 1.000 \\
\hline ACEI/ARB & $116(71.6)$ & $188(75.2)$ & 0.420 & $43(71.7)$ & $92(77.3)$ & 0.460 \\
\hline Diuretics & $126(77.8)$ & $37(14.8)$ & $<0.001$ & $53(88.3)$ & $15(12.6)$ & $<0.001$ \\
\hline Digitalis & $40(24.7)$ & $4(1.6)$ & $<0.001$ & $9(15.0)$ & $4(3.4)$ & 0.010 \\
\hline Statin & $146(90.1)$ & $240(96.0)$ & 0.020 & $51(85.0)$ & $117(98.3)$ & 0.001 \\
\hline Aspirin & $147(90.7)$ & $233(93.2)$ & 0.450 & $46(76.7)$ & $108(90.8)$ & 0.020 \\
\hline Heparin $^{\mathrm{a}}$ & $126(77.8)$ & $194(77.6)$ & 1.000 & $40(66.7)$ & $93(78.2)$ & 0.110 \\
\hline Clopidogrel & $156(96.3)$ & $246(98.4)$ & 0.200 & $57(95.0)$ & $115(96.7)$ & 0.690 \\
\hline Thrombolytic therapy & $22(13.6)$ & $30(12.0)$ & 0.650 & $1(1.7)$ & $3(2.5)$ & 1.000 \\
\hline \multicolumn{7}{|l|}{ Intervention } \\
\hline Cardiac angiography & $99(61.1)$ & $188(75.2)$ & 0.003 & $26(43.3)$ & $83(69.7)$ & 0.001 \\
\hline PCI & $78(48.1)$ & $167(66.8)$ & $<0.001$ & $18(30.0)$ & $65(54.6)$ & 0.002 \\
\hline TIMI flow grade at PCI 2-3 & $75(96.2)$ & $167(100.0)$ & - & $18(100.0)$ & $65(100.0)$ & - \\
\hline Numbers of diseased vessels ${ }^{c}$ & 99 & 188 & 0.170 & 26 & 83 & 0.500 \\
\hline One & $22(22.2)$ & $59(31.4)$ & - & $4(15.4)$ & $29(34.9)$ & - \\
\hline Two & $26(26.3)$ & $52(27.7)$ & - & $3(11.5)$ & $16(19.3)$ & - \\
\hline Three & $51(51.5)$ & $77(40.9)$ & - & $19(73.1)$ & $38(45.8)$ & - \\
\hline Culprit artery ${ }^{\mathrm{b}}$ & & & & 0.23 & & 0.350 \\
\hline Left anterior descending & $81(50.0)$ & $141(56.4)$ & - & $29(48.3)$ & $62(52.1)$ & - \\
\hline Right coronary & $63(38.9)$ & 87 (34.8) & - & $15(25.0)$ & $23(19.3)$ & - \\
\hline Circumflex & $16(9.9)$ & $15(6.0)$ & - & 0 & $5(4.2)$ & - \\
\hline Not localized & $2(1.2)$ & $7(2.8)$ & - & $16(26.7)$ & $29(24.4)$ & - \\
\hline
\end{tabular}

ancluding intravenous and subcutaneous heparin; ${ }^{b}$ The diagnosis of culprit artery was conducted according to the results of percutaneous coronary intervention and electrocardiogram. ${ }^{~}$ Numbers of vessels disease were analyzed according to patients who underwent cardiac angiography. Figures in parentheses are percentages. ACEI, angiotensin-converting enzyme inhibitor; AMI, acute myocardial infarction; ARB, angiotensin receptor blocker; CCB, calcium channel blockers; HF, heart failure; NSTEMI, non-ST-segment elevation myocardial infarction; PCI, percutaneous coronary intervention; STEMI, ST-segment elevation myocardial infarction.

Medical treatment. The medications prescribed to patients with AMI during hospitalization are listed in Table II. Antiarrhythmic agents and $\mathrm{HF}$ medication (such as diuretics and digitalis) were more often prescribed to post-AMI (both STEMI and NSTEMI) HF patients. Due to contraindications (including hemorrhagic disease and stomach disease) and incomplete original medication administration records in certain cases, aspirin was prescribed and thus some data bias may exist. According to standard medical norms, all patients diagnosed with AMI should receive aspirin treatment except in cases of severe contraindications. There were no clinically significant differences in the development of post-AMI HF following the use of aspirin, BBs and ACEIs, which serve a crucial function in the prevention of cardiac remodeling and in the treatment of simultaneous HF and AMI. Therefore, the use of BBs and ACEIs in patients with or without HF was further analyzed and the results are shown in Table III. Patients with HF during hospitalization treated with both classes of medication $(n=142)$ had a significantly higher survival rate compared with untreated patients or those treated with either class of medication alone ( $\mathrm{n}=80 ; 94.4$ vs. $67.5 \% ; \mathrm{P}<0.001)$, although the two subgroups had similar baseline characteristics. Patients with $\mathrm{HF}$ receiving neither BBs nor ACEIs had the lowest survival rate (Table III). However, AMI patients with HF that received both classes of recommended medication had a significantly lower survival rate compared with AMI patients without HF $(\mathrm{P}<0.001$; Fig. 1).

Notably, post-AMI patients with HF were less likely to undergo cardiac angiography and PCI compared with patients without $\mathrm{HF}(\mathrm{P}<0.05$; Table II). Although there were no significant differences in culprit vessels and vessel disease, as in the case of patients with NSTEMI, patients with STEMI that developed in-hospital HF had severe right coronary stenosis, left circumflex disease, or three vessel disease. 
Table III. Comparison of post-AMI patients with HF with or without BB and ACEI treatment.

\begin{tabular}{|c|c|c|c|}
\hline Variable & $\begin{array}{l}\text { HF patients with both } \\
\text { BB + ACEI }(n=142)\end{array}$ & $\begin{array}{l}\text { Untreated HF patients or treated } \\
\text { with either class of drug }(n=80)\end{array}$ & P-value \\
\hline Mean age (years) & $71.5 \pm 10.7$ & $71.7 \pm 9.8$ & 0.940 \\
\hline Men & $74(52.1)$ & $41(51.3)$ & 1.000 \\
\hline Diabetes mellitus & $43(30.3)$ & $15(18.8)$ & 0.080 \\
\hline Hypertension & $74(52.1)$ & $42(52.5)$ & 1.000 \\
\hline COPD & $16(11.3)$ & $15(18.8)$ & 0.160 \\
\hline Previous angina & $48(33.8)$ & $20(25.0)$ & 0.230 \\
\hline Chronic renal failure & $11(7.7)$ & $8(10.0)$ & 0.620 \\
\hline STEMI & $102(71.8)$ & $60(75.0)$ & 0.640 \\
\hline LVEF (\%) & $51.9 \pm 9.0$ & $51.9 \pm 6.7$ & 0.950 \\
\hline Killip class & & & 0.003 \\
\hline II & $95(66.9)$ & $40(50.0)$ & - \\
\hline III & $26(18.3)$ & $13(16.25)$ & - \\
\hline IV & $17(11.9)$ & $26(32.5)$ & - \\
\hline Heart beats (beats/min) & $85.9 \pm 22.0$ & $84.9 \pm 26.9$ & 0.750 \\
\hline Arrhythmia & $20(14.1)$ & $10(12.5$ & 0.790 \\
\hline $\mathrm{AF}$ & $16(16.3)$ & $7(8.75)$ & \\
\hline VA & $4(2.8)$ & $3(3.75)$ & \\
\hline Serum creatinine $^{\mathrm{a}}(\mu \mathrm{mol} / \mathrm{l})$ median (range) & $88.0(7.0,732.0)$ & $98.0(39.0,860.0)$ & 0.020 \\
\hline Urea nitrogen $(\mathrm{mmol} / \mathrm{l})$ & $8.23 \pm 4.94$ & $9.02 \pm 4.71$ & 0.250 \\
\hline $\mathrm{CKMB}^{\mathrm{a}}$ (ng/ml) median (range) & $19.50(0.2,493.1)$ & $28.90(0.1,500.0)$ & 0.059 \\
\hline PCI & $68(47.9)$ & $28(35.0)$ & 0.070 \\
\hline In-hospital cardiogenic shock & $21(14.8)$ & $28(35.0)$ & 0.001 \\
\hline In-hospital mortality & $8(5.6)$ & $26(32.5)$ & $<0.001$ \\
\hline
\end{tabular}

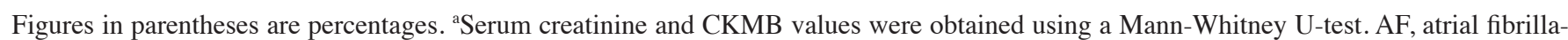
tion; AMI, acute myocardial infarction; ACEI, angiotensin-converting enzyme inhibitor; BB, $\beta$-blockers; CKMB, creatine kinase MB; COPD, chronic obstructive pulmonary disease; HF, heart failure; LVEF, left ventricular ejection fraction; PCI, percutaneous coronary intervention; STEMI, ST-segment elevation myocardial infarction; VA, ventricular arrhythmia.

Clinical outcomes. As shown in Table IV and Fig. 2, the in-hospital mortality rate was significantly higher in STEMI (15.4 vs. $3.3 \%$ ) and NSTEMI (15 vs. $0.8 \%$ ) patients with HF $(\mathrm{P}<0.001)$ compared with those without HF, as was the length of hospital stay. Non-fatal in-hospital outcomes such as atrial fibrillation and ventricular arrhythmia were significantly more frequent in post-AMI patients with $\mathrm{HF}(\mathrm{P}=0.001$ and $\mathrm{P}<0.001$, respectively); however, there were no significant differences in the rates of recurrent ischemia, major bleeding, re-infarction or high-grade atrioventricular blockage between $\mathrm{HF}$ and non-HF patients. The prevalence of MACEs was higher in HF patients with either type of AMI; post-AMI HF patients with MACEs had a higher risk of in-hospital mortality compared with those without MACEs ( $\mathrm{P}<0.001$; Table IV; Fig. 3).

Predictors of outcome. The logistic regression analysis performed to assess the effect of HF while adjusting for potential confounding factors is shown in Table V. Cardiogenic shock [odds ratio (OR), 8.21; 95\% confidence interval (CI), 2.75-24.48; $\mathrm{P}<0.001]$ following $\mathrm{AMI}$ was the strongest predictor of in-hospital mortality, in addition to the onset of HF (OR, 2.88; 95\% CI, 1.00-8.28; $\mathrm{P}=0.049)$ and age (OR, 1.07;
95\% CI, 1.02-1.12; $\mathrm{P}=0.006)$. Similarly, in-hospital mortality rates were over two times higher in patients with Killip class III and IV AMI compared with patients with Killip class I and II AMI (Fig. 4), indicating that Killip class was associated with in-hospital mortality. Conversely, treatment with oral BBs (OR, 0.43; 95\% CI, 0.61-0.92; $\mathrm{P}=0.045)$, treatment with ACEIs (OR, 0.41; 95\% CI, 0.49-0.87; $\mathrm{P}=0.041$ ), the CKMB value (OR, 1.003; 95\% CI, 1.00-1.01; $\mathrm{P}=0.038$ ) and length of hospital stay (OR, 0.93; 95\% CI, 0.87-0.99; $\mathrm{P}=0.034)$ were inversely correlated with in-hospital mortality. Co-treatment with BBs and ACEIs was associated with reduced mortality (OR, 0.24; 95\% CI, 0.16-0.37; P<0.001). Notably, a history of COPD was inversely associated with in-hospital mortality (OR, 0.05; 95\% CI, 0.00-0.67; $\mathrm{P}=0.023)$. The performance of cardiac angiography (OR, 0.12; 95\% CI, 0.04-0.35; $\mathrm{P}<0.001$ ) was associated with decreased in-hospital mortality. The logistic regression model demonstrated that patients with COPD in the overall AMI population had a reverse relationship with in-hospital mortality. Patients with AMI who presented with COPD were more likely to develop HF and have a higher prescription rate of diuretics and digitalis $(\mathrm{P}<0.05)$, but a reduced use of BBs $(\mathrm{P}<0.001$; Table VI). 
Table IV. Clinical outcomes of the study population.

\begin{tabular}{|c|c|c|c|c|c|c|}
\hline \multirow[b]{2}{*}{ Variable } & \multicolumn{2}{|c|}{ STEMI } & \multirow[b]{2}{*}{ P-value } & \multicolumn{2}{|c|}{ NSTEMI } & \multirow[b]{2}{*}{ P-value } \\
\hline & $\begin{array}{c}\mathrm{HF} \\
(\mathrm{n}=162)\end{array}$ & $\begin{array}{l}\text { Non-HF } \\
(\mathrm{n}=250)\end{array}$ & & $\begin{array}{c}\mathrm{HF} \\
(\mathrm{n}=60)\end{array}$ & $\begin{array}{c}\text { Non-HF } \\
(\mathrm{n}=119)\end{array}$ & \\
\hline In-hospital mortality & $25(15.4)$ & $8(3.2)$ & $<0.001$ & $9(15.0)$ & $1(0.8)$ & $<0.001$ \\
\hline Atrial fibrillation & $20(12.3)$ & $9(3.6)$ & 0.001 & $8(13.3)$ & $3(2.5)$ & 0.007 \\
\hline Major bleeding & $4(2.5)$ & $1(0.4)$ & 0.080 & 0 & 0 & - \\
\hline Ventricular arrhythmia & $28(17.3)$ & $14(5.6)$ & $<0.001$ & $7(11.7)$ & $9(7.6)$ & 0.410 \\
\hline Recurrent ischemia & $17(10.5)$ & $17(6.8)$ & 0.200 & $7(11.7)$ & $9(7.6)$ & 0.410 \\
\hline Re-MI & $2(1.2)$ & $4(1.6)$ & 1.000 & $2(3.3)$ & $2(1.7)$ & 1.000 \\
\hline Cardiogenic shock & $40(24.7)$ & 0 & - & $9(15.0)$ & 0 & - \\
\hline High-grade AVB & $4(2.5)$ & $7(2.8)$ & 1.000 & $2(3.3)$ & $4(3.4)$ & 1.000 \\
\hline MACEs & $82(50.6)$ & $41(16.4)$ & $<0.001$ & $21(35)$ & $21(17.6)$ & 0.015 \\
\hline Hospital stay (days) & $12.8 \pm 9.7$ & $9.4 \pm 5.3$ & $<0.001$ & $13.9 \pm 9.2$ & $9.2 \pm 4.9$ & $<0.001$ \\
\hline
\end{tabular}

Figures in parentheses are percentages. High AVB including second- and third-degree heart blockage. MACEs included atrial fibrillation, ventricular arrhythmia, major bleeding, cardiogenic shock, recurrent ischemia, and Re-MI. AVB, atrioventricular blockage; HF, heart failure; MACEs, major cardiovascular events; NSTEMI, non-ST-segment elevation myocardial infarction; Re-MI, recurrent myocardial infarction; STEMI, ST-segment elevation myocardial infarction.

\section{Discussion}

The present study demonstrated that AMI patients with HF were at a higher risk of adverse in-hospital outcomes and had a higher incidence of MACEs compared with AMI patients without HF. In particular, in-hospital mortality was close to five-fold higher in STEMI patients with HF, as compared with that of patients without HF and even higher in NSTEMI patients with HF (15.0 vs. $0.8 \%$ ). Cardiogenic shock and HF during hospitalization were strong predictors of in-hospital mortality. Medications such as BBs or ACEIs were insufficiently prescribed, although the prescription rate was higher compared with that indicated by previous studies $(20,21)$. AMI patients with HF who received neither class of recommended medications (BBs or ACEIs) had a significantly higher risk of in-hospital mortality compared with those treated with the recommended medications. In addition, they were less likely to be examined by cardiac angiography and were treated with reperfusion therapy.

In the present study, HF occurred in $38.3 \%$ of patients with STEMI and in $33.5 \%$ of patients with NSTEMI. This incidence was similar to rates reported in western countries (32.4 and 34\%, respectively) $(22,23)$, although the Killip class in the present study was higher compared with that reported in an earlier study (24). One possible reason for the higher Killip class may be a longer pre-hospital delay compared with studies conducted in western countries (mean time, $<6 \mathrm{~h}$ ) and a longer delay in revascularization (25). A previous study demonstrated that a shorter door-to-balloon time was associated with a decline in the incidence of cardiovascular events and therefore, improved outcome following AMI (26). Furthermore, not all patients underwent immediate cardiac angiography or were taken directly to a PCI-capable center (hospitals with doctors able and qualified to perform PCI). These results were concordant with those of a previous study, in which $\sim 50 \%$ of the patients with AMI were transferred to PCI-capable centers from an interim hospital without PCI capabilities (27). Pre-hospital system delays vary and are correlated with geographical and local factors such as urbanization and the availability of emergency medical services (28). Regardless of location (western countries or China), the time to reperfusion therapy for patients with STEMI transferred for primary PCI is often prolonged, with the guideline-recommended overall time of $<90$ min being achieved in only a minority of transferred patients (29). Considering the geography and traffic situation of southwestern China, the mean pre-hospital delay is unable to reach the guideline-recommended goals (30). The direct association between total ischemic time and severity of myocardial injury and mortality has been well-established for patients with STEMI (31). These results suggest that all efforts should be aimed at reducing total ischemic time to achieve improved prognosis and life expectancy.

As patients with $\mathrm{HF}$ are generally older and have co-morbidities, physicians may hesitate to recommend cardiac medications or procedures despite an advantageous risk-to-benefit ratio due to concerns regarding adverse effects (32). Cardiovascular drugs frequently prescribed to patients with HF were more frequently administered, except for BBs, ACEIs and aspirin. Although the utilization rate of BBs and ACEIs remained lower in patients with HF compared with AMI patients without HF during each period under study, the use of these two medications increased progressively for HF through the early 1990s $(33,34)$. However, the issue of a persistent gap between ideal practice and the actual use of ACEIs for HF cannot be ignored. It is difficult to close this gap in the adequate use of evidence-based medications due to numerous clinical conditions or complex natural and human factors (including co-morbid illnesses, economics, geography, ethnic or racial differences and genetic factors) $(10,11)$. Notably, the present analysis demonstrated that patients with the poorest cardiac function benefited as much as patients with better function. Data from the United States indicates that the percentage of patients receiving ACEIs or angiotensin-receptor blockers is $<80 \%$ (35), 
Table V. Predictors of in-hospital mortality.

\begin{tabular}{lccc}
\hline Variable & Adjusted OR & $95 \%$ CI & P-value \\
\hline Post-AMI HF & 2.88 & $1.00,8.28$ & 0.049 \\
Cardiogenic shock & 8.21 & $2.75,24.48$ & 0.000 \\
Age & 1.07 & $1.02,1.12$ & 0.006 \\
COPD & 0.05 & $0.00,0.67$ & 0.023 \\
Hospitalization days & 0.93 & $0.87,0.99$ & 0.034 \\
Antiarrhythmic agents & 4.59 & $1.84,11.51$ & 0.001 \\
B-blockers & 0.43 & $0.61,0.92$ & 0.045 \\
ACEIs & 0.41 & $0.49,0.87$ & 0.041 \\
Co-prescriptions & 0.24 & $0.16,0.37$ & 0.000 \\
Cardiac angiography & 0.12 & $0.04,0.35$ & 0.000 \\
CKMB & 1.00 & $1.00,1.01$ & 0.038 \\
\hline
\end{tabular}

ACEIs, angiotensin-converting enzyme inhibitors; AMI, acute myocardial infarction; CI, confidence interval; CKMB, creatine kinase MB; COPD, chronic obstructive pulmonary disease; Co-prescription, co-prescription of $\beta$-blockers and ACEIs; HF, heart failure; OR, odds ratio.

Table VI. Comparison of all AMI patients stratified according to COPD status.

\begin{tabular}{|c|c|c|c|}
\hline Variable & $\begin{array}{c}\text { COPD } \\
(n=50,8.5 \%)\end{array}$ & $\begin{array}{c}\text { Non-COPD } \\
(\mathrm{n}=541,91.5 \%)\end{array}$ & P-value \\
\hline $\mathrm{HF}$ & $31(62.0)$ & $191(35.3)$ & $<0.001$ \\
\hline Men & $28(56.0)$ & $287(53.0)$ & 0.770 \\
\hline Age & $74.2 \pm 8.1$ & $65.7 \pm 11.9$ & $<0.001$ \\
\hline Heart beats/min & $81.4 \pm 23.7$ & $79.6 \pm 19.8$ & 0.540 \\
\hline Serum creatinine $(\mu \mathrm{mol} / \mathrm{l})$ & $106.4 \pm 75.4$ & $93.7 \pm 63.6$ & 0.190 \\
\hline Urea nitrogen $(\mathrm{mmol} / \mathrm{l})$ & $8.7 \pm 6.1$ & $7.3 \pm 5.9$ & 0.090 \\
\hline $\mathrm{CKMB}^{\mathrm{a}}$ & $11.2(1.5,489.8)$ & $18.7(0.1,515.0)$ & 0.260 \\
\hline LVEF & $52.8 \pm 9.7$ & $54.8 \pm 7.5$ & 0.080 \\
\hline Hospital stay (days) & $10.7 \pm 6.8$ & $10.8 \pm 7.4$ & 0.890 \\
\hline STEMI & $31(62.0)$ & $381(70.4)$ & 0.260 \\
\hline ACEI & $36(72.0)$ & $403(74.5)$ & 0.740 \\
\hline$\beta$-blocker & $32(64.0)$ & $448(82.8)$ & 0.002 \\
\hline $\mathrm{CCB}$ & $13(26.0)$ & $135(24.9)$ & 0.870 \\
\hline Diuretics & $29(58.0)$ & $202(37.3)$ & 0.006 \\
\hline Digitalis & $10(20.0)$ & $48(8.7)$ & 0.020 \\
\hline Clopidogrel & $48(96.0)$ & $526(97.2)$ & 0.650 \\
\hline Aspirin & $45(90.0)$ & $489(90.4)$ & 0.810 \\
\hline Thrombolytic therapy & $1(2)$ & $55(10.2)$ & 0.070 \\
\hline PCI & $19(38.0)$ & $309(57.1)$ & 0.010 \\
\hline Three-vessel disease & $9(18.0)$ & $176(32.5)$ & 0.070 \\
\hline TIMI flow grade at PCI 2-3 & $18(36.0)$ & $307(56.7)$ & 0.160 \\
\hline In-hospital cardiogenic shock & $4(8.0)$ & $45(8.3)$ & 1.000 \\
\hline
\end{tabular}

aDetermined using the Mann-Whitney U-test. Figures in parentheses are percentages and continuous variables are means \pm standard deviation. ACEI, angiotensin-converting enzyme inhibitor; AMI, acute myocardial infarction; CCB, calcium channel blockers; CKMB, creatine kinase MB; COPD, chronic obstructive pulmonary disease; LVEF, left ventricular ejection fraction; PCI, percutaneous coronary intervention; STEMI, ST-segment elevation myocardial infarction.

whereas in western Australia, the prescription rate is $71 \%$ (36). Differences in ethnicity have been reported among these patients with HF with preserved systolic function (the BB prescription rate is $80 \%$ in Caucasians, $13.4 \%$ in African Americans, $1.0 \%$ in Asians and $0.4 \%$ in Native Americans). Another study demonstrated that African Americans with hypertension do not respond 
as well as Caucasians to treatment with BB, which may be due to differences in the sympathetic nervous system or in the use of drugs $(37,38)$. According to East Asian studies, patients with HF had a better utilization rate of ACEIs (70-90\%) and BBs $(60-70 \%)(12,39)$, which may partly explain the lower mortality rate $(2.3 \%, 6.6 \%)$. Patients treated with ACEIs and BBs had a lower all-cause mortality rate, lower cardiovascular mortality rate and higher long-term survival rate $(33,36,40)$. In certain metropolitan regions of China, the utilization rates of ACEIs and BBs were $\sim 70$ and $50 \%$ among patients with HF, respectively $(41,42)$, whereas the utilization rate of BBs was $<40 \%$ in general hospitals (43) and lower in rural areas. The prescription rates of ACEIs $(42.8-68.4 \%)(22,44)$ and BBs $(37.7-77 \%)(36,45)$ in previous studies in other countries were lower compared with those reported in the present study (ACEIs, 71.6\% and BBs, 74.7-90\%), which may partly explain the higher short-term mortality rates in the previous studies (15.9-17.7\%) compared with those of the present study (15-15.4\%). Furthermore, the MONICA plan (Sino-MONICA project) reported that the annual morbidity and mortality of Chinese patients with cardiovascular disease are below worldwide rates and similar rates were observed in Japan, Korea and other Asian countries (46). As the first-line therapy for AMI with HF according to the European Society of Cardiology guidelines for the diagnosis and treatment of HF (47), treatment with ACEIs should be administered in all patients with preserved ejection fraction as rapidly as possible following $\mathrm{HF}$ diagnosis and maintained during the various stages, unless there is a contraindication. Oral BBs should be initiated in the first $24 \mathrm{~h}$ in patients with STEMI without severe contraindications. Following logistic regression, treatment with BBs or ACEIs had a beneficial effect against in-hospital mortality, whereas calcium-channel blockers did not affect in-hospital mortality $(48,49)$. Meta-analyses of the use of ACEIs in patients with AMI and left ventricular systolic dysfunction showed a significant reduction in cardiovascular events and mortality with ACEI use. International recommendations emphasize the protective role of BBs in patients with both AMI and HF (50,51). However, further efforts are required to reduce the gap between ideal practice and the actual use of recommended medications in China due to a deficient medical system and an underdeveloped medical information system, in a country with cultural and demographic similarities and geographical and social and physical environmental differences (52). China is currently undergoing rapid socioeconomic changes further to economic reforms, particularly, increases in the gross national product, average income and personal expenditure have been reported (46). Further studies are required in order to investigate the differences between Asia and the rest of the world and to identify the most effective ways to improve the utilization rate of recommended medications that have recently become more available.

In line with the results of previous studies, the present study demonstrated that AMI patients with HF were less likely to undergo primary PCI than non-HF patients $(22,23)$. Early revascularization has been shown to decrease infarct size, improve cardiac function and decrease the rate of cardiogenic shock. Although studies have reported the survival benefit of thrombolysis and PCI in patients with HF (53), other studies including the present one have not (54). Thrombolysis and PCI are negatively associated with in-hospital mortality in patients with HF, which may be explained by prolonged pre-hospital delay, lower reperfusion rates, associated mechanical complications (such as mitral regurgitation) or complete infarction. The limited sample size, short-term follow-up and unavoidable sample bias in the present study may have masked the positive effects of the revascularization strategy. According to the 2013 American College of Cardiology Foundation/American Heart Association guidelines for MI, primary PCI is the recommended method of reperfusion when it can be performed in a timely manner ( $\leq 90 \mathrm{~min})$ by experienced operators. However, if thrombolysis therapy is indicated or selected as the primary reperfusion strategy, it should be administered within $30 \mathrm{~min}$ of hospital arrival (30). Similar to the results of previous studies $(54,55)$, cardiac angiography had a positive effect on in-hospital mortality, likely due to the fact that cardiac angiography can be used to grade the complexity and extent of AMI and patients can receive relevant therapy accordingly in a timely and appropriate manner. In addition, cardiac angiography can be used to assess the requirement for revascularization therapy for lesions, the number of diseased coronary arteries and the location and calcification of the vessels that determine AMI complexity (54). However, further investigation is required to clarify whether primary PCI is superior to thrombolysis therapy for AMI patients with HF.

In the present study, the in-hospital mortality rate was $15-15.4 \%$ in the HF group, in the mid-range of previously reported in-hospital mortality rates in western countries (21.6\%) (22) and China (12.3\%) (56). Certain hospital-based studies in China have reported short-term mortality rates following AMI ranging from 8.1-13.1\% (41,57), which was higher compared with that in South Asian and Caucasian patients. This may be partly explained by a delayed presentation to emergency departments from the onset of AMI symptoms (58). Considering the large and complex population in China, health education in cardiovascular patients as well as in healthy individuals is lacking, resulting in lack of attention in acute severe cases. In contrast to numerous studies $(59,60)$, the logistic regression model of the present study for the overall AMI population demonstrated that COPD was inversely correlated with in-hospital mortality. AMI patients with COPD were more likely to develop $\mathrm{HF}$ and had higher prescription rates of diuretics and digitalis $(\mathrm{P}<0.05)$, but a lower $\mathrm{BB}$ prescription rate $(\mathrm{P}=0.002)$. It is plausible that in these patients with COPD, the alterations in inflammation, endothelial function and associated platelet reactivity may have destabilized the underlying coronary disease. As a result of inflammation, patients with COPD had a decreased platelet volume and an increased platelet count (61). Marked platelet inhibition may reduce cardiac adverse events in patients with COPD; however, this hypothesis requires validation (62). Another explanation may be that COPD patients suffered from chronic hypoxia, which is responsible for hemodynamic changes and the activation of the rennin-angiotensin system. Therefore, these patients with COPD may have a strong tolerance against the pathological changes of MI or HF; further studies are required to clarify the underlying mechanisms. The present cross-sectional study only assessed prognosis in terms of length of hospital stay (in-hospital mortality), which limited a long-term follow-up to determine whether the short-term and long-term prognoses of AMI patients with COPD differ. The Sino-MONICA project demonstrated that in China, cardiovascular disease mortality and risk factor levels were higher in the north and lower in the south (63). Similar to previous findings, a higher Killip class was associated with increased hospital mortality, and therefore the 
Killip classification serves as an accurate tool for early risk assessment of in-hospital mortality in patients with AMI (64). Although the incidence and survival rates of patients with HF have improved in the last decade (13), the association between a higher Killip class and worse prognosis has not changed.

Several limitations and strengths are noteworthy in the present study. Firstly, in an HF setting with a short hospital stay, medications could not reach the recommended level of titration. Secondly, patients with HF could not undergo cardiac angiography and rapidly receive sufficient therapy due to their poor condition. However, this study has notable strengths as well. Data from the hospital are real-case observations and were collected consecutively. With these representative data, the present investigation demonstrated how AMI was managed in daily clinical practice in southwestern China and thus demonstrate how it may be improved.

The present results demonstrated that AMI patients with HF have a higher mortality rate and are at greater risk of hospital-associated adverse outcomes compared with AMI patients without HF in Southwestern China. Guideline-recommended medications and invasive testing are used less frequently in these patients. In China, the persistent gap between ideal practice and actual use of ACEIs and $\mathrm{BBs}$ for HF cannot be ignored. The performance of precise diagnostic methods such as cardiac angiography and timely administration of standard recommended medications were associated with improved in-hospital mortality.

\section{Acknowledgements}

The authors of the present study are grateful to all the participating professors and students, specifically Dr Michael Fu of the Sahlgrenska University Hospital/Östra Hospital and the staff at the The First Affiliated Hospital of Chongqing Medical University for their helpful cooperation. The study was supported by the National Key Clinical Specialties Construction Program of China (grant no. 170).

\section{References}

1. World Health Organization: Cardiovascular diseases: Fact sheet 317. http://www.who.int/mediacentre/factsheets/fs317/en/index.html. Accessed March 19, 2016.

2. Zhao S, Zhang Z, Long Q, Ma Y, Lian X, Yang Y, Gao W, Chen X and Wang L: Association between time of day of sports-related physical activity and the onset of acute myocardial infarction in a Chinese population. PLoS One 11: e0146472, 2016.

3. Baron T, Hambraeus K, Sundström J, Erlinge D, Jernberg T and Lindahl B; TOTAL-AMI study group: Type 2 myocardial infarction in clinical practice. Heart 101: 101-106, 2015.

4. Xu T,Li W, Teo K, Wang XY,Liu LS and Yusuf S; INTER-HEART China Investigators: Association of psychological risk factors and acute myocardial infarction in China: The INTER-HEART China study. Chin Med J (Engl) 124: 2083-2088, 2011.

5. Wolff JL, Starfield B and Anderson G: Prevalence, expenditures, and complications of multiple chronic conditions in the elderly. Arch Intern Med 162: 2269-2276, 2002.

6. Schmidt M, Jacobsen JB, Lash TL, BØtker HE and SØrensen HT: 25 year trends in first time hospitalization for acute myocardial infarction, subsequent short and long term mortality, and the prognostic impact of sex and comorbidity: A Danish nationwide cohort study. BMJ 344: e356, 2012.

7. Cabiddu R, Trimer R, Monteiro CI, Borghi-Silva A, Trimer V, Carvalho P, Rocha T, Paredes S, Bianchi AM and Henriques J: Correlation between autonomous function and left ventricular performance after acute myocardial infarction. Conf Proc IEEE Eng Med Biol Soc 2015: 3343-3346, 2015.
8. Hunt SA, Abraham WT, Chin MH, Feldman AM, Francis GS, Ganiats TG, Jessup M, Konstam MA, Mancini DM, Michl K, et al. ACC/AHA 2005 guideline update for the diagnosis and management of chronic heart failure in the adult: a report of the American College of Cardiology/American Heart Association Task Force on Practice Guidelines (Writing Committee to Update the 2001 Guidelines for the Evaluation and Management of Heart Failure). American College of Cardiology. http://www.acc.org/clinical/guidelines/failure//index.pdf. Accessed, December 17, 2015.

9. Greco C, Rosato S, D'Errigo P, Mureddu GF, Lacorte E and Seccareccia F: Trends in mortality and heart failure after acute myocardial infarction in Italy from 2001 to 2011. Int J Cardiol 184: 115-121, 2015.

10. Kramer JM, Newby LK, Chang WC, Simes RJ, Van de Werf F, Granger CB, Lee KL, White HD, Piegas LS, Topol EJ, et al; SYMPHONY and 2nd SYMPHONY Investigators: International variation in the use of evidence-based medicines for acute coronary syndromes. Eur Heart J 24: 2133-2241, 2003.

11. Fischbacher CM, Bhopal R, Povey C, Steiner M, Chalmers J, Mueller G, Jamieson J and Knowles D: Record linked retrospective cohort study of 4.6 million people exploring ethnic variations in disease: Myocardial infarction in South Asians. BMC Public Health 7: 142, 2007.

12. Yoo BS, Oh J, Hong BK, Shin DH, Bae JH, Yang DH, Shim WJ, Kim HS, Kim SH, Choi JO, et al: Survey of guideline adherence for treatment of systolic heart failure in real world (SUGAR): A multi-center, retrospective observational study. PLoS One 9: e86596, 2014.

13. Gjesing A, Schou M, Torp-Pedersen C, Køber L, Gustafsson F, Hildebrandt P, Videbæk L, Wiggers H, Demant M, Charlot M and Gislason GH: Patient adherence to evidence-based pharmacotherapy in systolic heart failure and the transition of follow-up from specialized heart failure outpatient clinics to primary care. Eur J Heart Fail 15: 671-678, 2013.

14. Chongqing Municipality Bureau of Statistics. Chongqing Statistical Yearbook 2015. Chines Statistics Press, Beijing, 2015.

15. Thygesen K, Alpert JS, Jaffe AS, Simoons ML, Chaitman BR and White HD; Writing Group on behalf of the Joint ESC/ACCF/AHA/WHF Task Force for the Universal Definition of Myocardial Infarction: Third universal definition of myocardial infarction. Glob Heart 7: 275-295, 2012.

16. Juillière Y, Cambou JP, Bataille V, Mulak G, Galinier M, Gibelin P, Benamer H, Bouvaist H, Méneveau N, Tabone X, et al: Heart failure in acute myocardial infarction: A comparison between patients with or without heart failure criteria from the FAST-MI registry. Rev Esp Cardiol (Engl Ed) 65: 326-333, 2012.

17. Yancy CW, Jessup M, Bozkurt B, Butler J, Casey DE Jr, Drazner MH, Fonarow GC, Geraci SA, Horwich T, Januzzi JL, et al: 2013 ACCF/AHA guidelines for the management of heart failure: A report of the American college of cardiology foundation/American heart association task force on practice guideline. J Am Coll Cardilo 62: e147-e239, 2013.

18. Goldberg RJ, Spencer FA, Gore JM, Lessard D and Yarzebski J: Thirty-year trends (1975 to 2005) in the magnitude of, management of and hospital death rates associated with cardiogenic shock in patients with acute myocardial infarction: A population-based persective. Circulation 119: 1211-1219, 2009.

19. Pham PA, Pham PT, Pham PC, Miller JM, Pham PM and Pham SV: Implications of bleeding in acute coronary syndrome and percutaneous coronary intervention. Vasc Health Risk Manag 7: 551-567, 2011.

20. Andersson C, Mérie C, Jørgensen M, Gislason GH, Torp-Pedersen C, Overgaard C, Køber L, Jensen PF and Hlatky MA: Association of $\beta$-blocker therapy with risks of adverse cardiovascular events and deaths in patients with ischemic heart disease undergoing noncardiac surgery: A Danish nationwide cohort study. JAMA Intern Med 174: 336-344, 2014.

21. Hersi A, Alhabib KF, Alsheikh-Ali AA, Sulaiman K, Alfaleh HF, Alsaif S, Al-Mahmeed W, Asaad N, Amin H, Al-Motarreb A and Al Suwaidi J: Short-term and long-term mortality associated with ventricular arrhythmia in patients hospitalized with acute coronary syndrome: Findings from the Gulf RACE registry-2. Coron Artery Dis 24: 160-164, 2013.

22. McManus DD, Chinali M, Saczynski JS, Gore JM, Yarzebski J, Spencer FA, Lessard D and Goldberg RJ: 30-year trends in heart failure in patients hospitalization with acute myocardial infarction. Am J Cardiol 107: 353-359, 2011. 
23. Kaul P, Ezekowitz JA, Armstrong PW, Leung BK, Savu A, Welsh RC, Quan H, Knudtson ML and McAlister FA: Incidence of heart failure and mortality after acute coronary syndromes. Am Heart J 165: 379-385.e2, 2013.

24. Gupta T, Harikrishnan P, Kolte D, Khera S, Subramanian KS, Mujib M, Masud A, Palaniswamy C, Sule S, Jain D, et al: Trends in management and outcomes of ST-elevation myocardial infarction in patients with end-stage renal disease in the United States. Am J Cariol 115: 1033-1041, 2015.

25. Geng W, Tian X, Fu X, Wang P, Wang Y, Wang X, Li W and Liu X: Early routine angioplasty versus selective angioplasty after successful thrombolysis in acute ST-segment elevation myocardial infarction. Coron Artery Dis 24: 238-243, 2013.

26. Poulin MF, Appis A, Purim-Shem-Tov Y, Schaer GL and Snell J: Impact of a Novel international platform and hospital design on the door-to-balloon time in patients presenting with ST-segment elevation myocardial infarction. Crit Pathw Cardiol 14: 39-43, 2015.

27. Concannon TW, Nelson J, Goetz J and Griffith JL: A percutaneous coronary intervention lab in every hospital? Circ Cardiovasc Qual Outcomes 5: 14-20, 2012.

28. Fosbøl EL, Granger CB, Peterson ED, Lin L, Lytle BL, Shofer FS, Lohmeier C, Mears GD, Garvey JL, Corbett CC, et al: Prehospital system delay in ST-segment elevation myocardial infarction care: A novel linkage of emergency medicine services and inhospital registry data. Am Heart J 165: 363-370, 2013.

29. Koul S, Andell P, Martinsson A, Gustav Smith J, van der Pals J, Scherstén F, Jernberg T, Lagerqvist B and Erlinge D: Delay from first medical contact to primary PCI and all-cause mortality: A nationwide study of patients with ST-elevation myocardial infarction. J Am Heart Assoc 3: e000486, 2014.

30. O'Gara PT, Kushner FG, Ascheim DD, Casey DE Jr, Chung MK, de Lemos JA, Ettinger SM, Fang JC, Fesmire FM, Franklin BA, et al; CF/AHA Task Force: 2013 ACCF/AHA guideline for the management of ST-elevation myocardial infarction: executive summary: A report of the American College of Cardiology Foundation/American Heart Association Task Force on Practice Guidelines. Circulation 127: 529-555, 2013.

31. Minha S, Loh JP, Satler LF, Pendyala LK, Barbash IM, Magalhaes MA, Suddath WO, Pichard AD, Torguson R and Waksman R: Transfer distance effect on reperfusion: Timeline of ST-elevation patients transferred for primary percutanenous coronary intervention. Cardiovasc Revasc Med 15: 369-374, 2014.

32. Lazzarini V, Mentz RJ, Fiuzat M, Metra M and O'Connor CM: Heart failure in elderly patients: Distinctive features and unresolved issue. Eur J Heart Fail 15: 717-723, 2013.

33. Ong HT, Ong LM and Ho JJ: Angiotensin-converting enzyme inhibitors (ACEIs) and angiotensin-receptor blockers (ARBs) in patients at high risk of cardiovascular events: A meta-analysis of 10 randomized placebo-controlled trials. ISRN Cardiol 2013: 478597, 2013.

34. Hernandez AF, Hammill BG, O'Connor CM, Schulman KA, Curtis LH and Fonarow GC: Clinical effectiveness of beta-blockers in heart failure: Findings from the OPTIMIZE-HF (organized program to initiate lifesaving treatment in hospitalized patients with heart failure) registry. J Am Coll Cardiol 53: 184-192, 2009.

35. Eschalier R, Chenaf C, Mulliez A, Yalioua A, Clerfond G, Authier N, Vorilhon C, Citron B, Pereira B, Jean F, et al: Impact of clinical characteristics and management on the prognosis of unselected heart failure patients. Cardiovasc Drugs Ther 29: 89-98, 2015

36. Hung J, Teng TH, Finn J, Knuiman M, Briffa T, Stewart S, Sanfilippo FM, Ridout S and Hobbs M: Trends from 1996 to 2007 in incidence and mortality outcomes of heart failure after acute myocardial infarction: A population-based study of 20 , 812 patients with first acute myocardial infarction in Western Australia. J Am Heart Assoc 2: e000172, 2013.

37. Materson BJ, Reda DJ, Cushman WC, Massie BM, Freis ED, Kochar MS, Hamburger RJ, Fye C, Lakshman R, Gottdiener J, et al; The Department of Veterans Affairs Cooperative Study Group on Antihypertensive Agents: Single-drug therapy for hypertension in men: A comparison of six antihypertensive agents with placebo. N Engl J Med 328: 914-921, 1993.

38. Prisant LM and Mensah GA: Use of beta-adrenergic receptor blockers in blacks. J Clin Pharmacol 36: 867-873, 1996.
39. Youn YJ, Yoo BS, Lee JW, Kim JY, Han SW, Jeon ES, Cho MC, Kim JJ, Kang SM, Chae SC, et al; KorHF Registry: Treatment performance measures affect clinical outcomes in patients with acute systolic heart failure. Circ J 76: 1151-1158, 2012.

40. Gomez-Soto FM, Romero SP, Bernal JA, Escobar MA, Puerto JL, Andrey JL, Almenara J and Gomez F: Mortality and morbidity of non-systolic heart failure treated with angiotensin-converting enzyme inhibitors: A propensity-adjusted case-control study. Int J Cardiol 139: 276-282, 2010.

41. Guo S, Yang Z, Wu D, Yang C, Tao Y, Chen F, Su W, Zheng R, Yang S, Li X and Chen J: A multi-centre survey on the therapeutic status of patients with acute myocardial infarction in Wuxi city of China. Zhonghua Xin Xue Guan Bing Za Zhi 42: 309-313, 2014.

42. Lai EJ, Grubisic M, Palepu A, Quan H, King KM and Khan NA: Cardiac medication prescribing and adherence after acute myocardial infarction in Chinese and South Asian Canadian patients. BMC Cardiovasc Disord 11: 56, 2011.

43. Jiang $\mathrm{H}$ and $\mathrm{Ge} \mathrm{J}$ : Epidemiology and clinical management of cardiomyopathies and heart failure in China. Heart 95: 1727-1731, 2009.

44. Teo KK, Liu L, Chow CK, Wang X, Islam S, Jiang L, Sanderson JE, Rangarajan S and Yusuf S; INTERHEART Investigators in China: Potential modifiable risk factors associated with myocardial infarction in China: The INTERHEART China study. Heart 95: 1857-1864, 2009.

45. Doughty RN, Rodgers A, Sharpe N and MacMahon S: Effects of beta-blocker therapy on mortality in patients with heart failure: A systematic overview of randomized controlled trails. Eur Heart J 18: 560-565, 1997.

46. Yang ZJ, Liu J, Ge JP, Chen L, Zhao ZG and Yang WY; China National Diabetes and Metabolic Disorders Study Group: Prevalence of cardiovascular disease risk factor in the Chinese population: The 2007-2008 China National Diabetes and Metabolic Disorders Study. Eur Heart J 33: 213-220, 2012.

47. McMurray JJ, Adamopoulos S, Anker SD, Auricchio A, Böhm M, Dickstein K, Falk V, Filippatos G, Fonseca C, Gomez-Sanchez MA, et al; ESC Committee for Practice Guidelines: ESC Guidelines for the diagnosis and treatment of acute and chronic heart failure 2012: The Task Force for the Diagnosis and Treatment of Acute and Chronic Heart Failure 2012 of the European Society of Cardiology. Developed in collaboration with the Heart Failure Association (HFA) of the ESC. Eur Heart J 33: 1787-1847, 2012.

48. Strauss MH and Hall AS: The divergent cardiaovascular effects of angiotensin converting enzyme inhibitors and angiotensin receptor blockers on myocardial infarction and death. Prog Cardiovasc Dis: Nov 14, 2015 (Epub ahead of print).

49. Xie W, Zheng F, Song X, Zhong B and Yan L: Renni-angiotensin-aldosterone system blockers for heart failure with reduced ejection fraction or left ventricular dysfunction: Network meta-analysis. Int J Cardiol 205: 65-71, 2016.

50. Swedberg K, Cleland J, Dargie H, Drexler H, Follath F, Komajda M, Tavazzi L, Smiseth OA, Gavazzi A, Haverich A, et al: Task Force for the Diagnosis and Treatment of Chronic Heart Failure of the European Society of Cardiology: Guidelines for the diagnosis and treatment of chronic heart failure: Executive summary (update 2005): The Task Force for the Diagnosis and Treatment of Chronic Heart Failure of the European Society of Cardiology. Eur Heart J 26: 1115-1140, 2005.

51. Van de Werf F, Ardissino D, Betriu A, Cokkinos DV, Falk E, Fox KA, Julian D, Lengyel M, Neumann FJ, Ruzyllo W, et al; Task Force on the Management of Acute Myocardial Infarction of the European Society of Cardiology: Management of acute myocardial infarction in patients presenting with ST-segment elevation. Eur Heart J 24: 28-66, 2003.

52. Dang H, Wang Q, Wang H, Yan M and Liu X: The integration of Chinese material medica into the Chinese Health Care Delivery System, an update. Phytother Res 30: 292-297, 2016.

53. Huynh T, Perron S, O'Loughlin J, Joseph L, Labrecque M, Tu JV and Théroux P: Comparison of primary percutaneous coronary intervention and fibrinolytic therapy in ST-segment-elevation myocardial infarction: Bayesian hierarchical meta-analyses of randomized controlled trials and observational studies. Circulation 119: 3101-3109, 2009.

54. Harjola VP, Follath F, Nieminen MS, Brutsaert D, Dickstein K, Drexler H, Hochadel M, Komajda M, Lopez-Sendon JL, Ponikowski P and Tavazzi L: Characteristics, outcomes and predictors of mortality at 3 months and 1 year in patients hospitalized for acute heart failure. Eur J Heart Fail 12: 239-248, 2010. 
55. Goldberg RJ, Samad NA, Yarzebski J, Gurwitz J, Bigelow C and Gore JM: Temporal trends in cardiogenic shock complicating acute myocardial infarction. N Engl J Med 340: 1162-1168, 1999.

56. Khan NA, Grubisic M, Hemmelgarn B, Humphries K, King KM and Quan H: Outcomes after acute myocardial infarction in South Asia, Chinese, and white patients. Circulation 122: 1570-1577, 2010.

57. Zhou L, Honma T and Kaku N: Comparison of incidence, mortality and treatment of acute myocardial infarction in hospitals in Japan and China. Kurume Med J 39: 279-284, 1992.

58. Jones DA, Gallagher S, Rathod KS, Redwood S, de Belder MA, Mathur A, Timmis AD, Ludman PF, Townend JN and Wragg A; NICOR (National Institute for Cardiovascular Outcomes Research): Mortality in South Asians and Caucasians after percutaneous coronary intervention in the United Kingdom: An observational cohort study of 279,256 patients from the BCIS (British cardiovascular intervention society) national database. JACC Cardiovasc Interv 7: 362-371, 2014

59. Campo G, Guastaroba P, Marzocchi A, Santarelli A, Varani E, Vignali L, Sangiorgio P, Tondi S, Serenelli C, De Palma R and Saia F: Impact of COPD on long-term outcome after ST-segment elevation myocardial infarction receiving primary percutaneous coronary intervention. Chest 144: 750-757, 2013.
60. Vestbo J,Hurd SS,Agustí AG,JonesPW,Vogelmeier C, Anzueto A, Barnes PJ, Fabbri LM, Martinez FJ, Nishimura M, et al: Global stragegy for the diagnosis, management and prevention of chronic obstructive pulmonary disease: GOLD executive summary. Am J Respir Cirt Care Med 187: 347-365, 2013.

61. Wang RT, Li JY, Cao ZG and Li Y: Mean platelet volume is decreased during an acute exacerbation of chronic obstructive pulmonary disease. Respirology 18: 1244-1248, 2013.

62. Campo G, Pavasini R, Malagù M, Punzetti S, Napoli N, Guerzoni F, Papi A, Ceconi C and Contoli M: Relationship between troponin elevation, cardiovascular history and adverse events in patients with acute exacerbation of COPD. COPD 12: 560-567, 2015

63. Wu Z, Yao C, Zhao D, Wu G, Wang W, Liu J, Zheng Z and Wu Y: Sino-MONICA project: A collaborative study on trends and determinants in cardiovascular diseases in China, Part $\mathrm{i}$ : Morbidity and mortality monitoring. Circulation 103: 462-468, 2001.

64. Mello BH, Oliveira GB, Ramos RF, Lopes BB, Barros CB, Carvalho Ede O, Teixeira FB, Arruda GD, Revelo MS and Piegas LS: Validation of the Killip-Kimball classification and late mortality after acute myocardial infarction. Arq Bras Cardiol 103: 107-117, 2014 (In English and Portuguese). 